Article

\title{
Studies on the Volatiles Composition of Stored Sheep Wool, and Attractancy toward Aedes aegypti Mosquitoes
}

\author{
Maia Tsikolia ${ }^{1, *}$, Nurhayat Tabanca ${ }^{2} \mathbb{D}$, Daniel L. Kline ${ }^{3}$, Betul Demirci ${ }^{4}$, Liu Yang ${ }^{5}$, Kenneth J. Linthicum ${ }^{3}$, \\ Jeffrey R. Bloomquist ${ }^{5}$ iD and Ulrich R. Bernier ${ }^{3, *}$
}

1 European Biological Control Laboratory, U.S. Department of Agriculture-Agricultural Research Service (USDA-ARS), 54623 Thessaloniki, Greece

2 Subtropical Horticulture Research Station (SHRS), U.S. Department of Agriculture-Agricultural Research Service (USDA-ARS), Miami, FL 33158, USA; nurhayat.tabanca@usda.gov

3 Center for Medical, Agricultural, and Veterinary Entomology (CMAVE), U.S. Department of Agriculture-Agricultural Research Service (USDA-ARS), Gainesville, FL 32608, USA; dan.kline@usda.gov (D.L.K.); kenneth.linthicum@usda.gov (K.J.L.)

4 Department of Pharmacognosy, Faculty of Pharmacy, Anadolu University, Eskisehir 26470, Turkey; bdemirca@anadolu.edu.tr

5 Department of Entomology and Nematology, Emerging Pathogens Institute, University of Florida, Gainesville, FL 32610, USA; lzy0017@tigermail.auburn.edu (L.Y.); jbquist@epi.ufl.edu (J.R.B.)

* Correspondence: m.tsikolia@gmail.com (M.T.); ubernier@cox.net (U.R.B.)

Citation: Tsikolia, M.; Tabanca, N.; Kline, D.L.; Demirci, B.; Yang, L.; Linthicum, K.J.; Bloomquist, J.R.; Bernier, U.R. Studies on the Volatiles Composition of Stored Sheep Wool, and Attractancy toward Aedes aegypti Mosquitoes. Insects 2022, 13, 208.

https://doi.org/10.3390/

insects13020208

Academic Editors: Andre Barreto Bruno Wilke and Mauro

Toledo Marrelli

Received: 13 January 2022

Accepted: 16 February 2022

Published: 18 February 2022

Publisher's Note: MDPI stays neutral with regard to jurisdictional claims in published maps and institutional affiliations.

Copyright: (C) 2022 by the authors. Licensee MDPI, Basel, Switzerland. This article is an open access article distributed under the terms and conditions of the Creative Commons Attribution (CC BY) license (https:// creativecommons.org/licenses/by/ $4.0 /)$
Simple Summary: In order to discover new natural remedies for controlling insect vectors, stored sheep wool was tested for its attractiveness to mosquitoes. The volatile compounds from the wool were collected. A total of 52 compounds were detected; many of them known to have mosquito attractant activity against various species. The most abundant compound in the sheep wool hydrodistillate was not attractive for female adult Aedes aegypti mosquitoes in small-scale lab evaluations. Comparative evaluations of raw sheep wool in two semi-field, large, screened outdoor cages each with bait equipped with a U.S. Centers for Disease Control (CDC) trap, revealed the bait with vibrated sheep wool was the best attractant for female adult Ae. aegypti mosquitoes compared to the setups without wool or not vibrated. It was concluded that sheep wool, an easily available, affordable, and environment-friendly material, could be considered as a potential tool to be used in dynamic bait setups for mosquito management and surveillance.

Abstract: To discover new natural materials for insect management, commercially available stored sheep wool was investigated for attractancy to female adult Aedes aegypti mosquitoes. The volatiles from sheep wool were collected by various techniques of headspace (HS) extractions and hydrodistillation. These extracts were analyzed using gas chromatography-mass spectrometry (GC-MS) and gas chromatography-flame ionization detector (GC-FID) coupled with GC-MS. Fifty-two volatile compounds were detected, many of them known for their mosquito attractant activity. Seven compounds were not previously reported in sheep products. The volatile composition of the extracts varied significantly across collections, depending on the extraction techniques or types of fibers applied. Two types of bioassay were conducted to study attractancy of the sheep wool volatiles to mosquitoes: laboratory bioassays using glass tubes, and semi-field bioassays using large, screened outdoor cages. In bioassays with glass tubes, the sheep wool hydrodistillate and its main component, thialdine, did not show any significant attractant activity against female adult $A e$. aegypti mosquitoes. Semi-field bioassays in two large screened outdoor cages, each equipped with a U.S. Centers for Disease Control (CDC) trap and the various bait setups with Vortex apparatus, revealed that vibrating wool improved mosquito catches compared to the setups without wool or with wool but not vibrating. Sheep wool, when vibrated, may release intensively volatile compounds, which could serve as olfactory cues, and play significant role in making the bait attractive to mosquitoes. Sheep wool is a readily available, affordable, and environment-friendly material. It should have the potential to be used as a mosquito management and surveillance component in dynamic bait setups. 
Keywords: GC-FID; GC-MS; hydrodistillation; SPME; HS-Hayesep-Q; semiochemicals

\section{Introduction}

In this study, we aimed to investigate natural means for spatial protection against mosquito bites and/or find new tools for surveillance purposes. Vector-borne diseases such as malaria, lymphatic filariases, schistosomiasis, leishmaniasis, onchocerciasis, trypanosomiasis, dengue, yellow fever and Japanese encephalitis, produce significant morbidity and mortality in humans and livestock, mostly in the developing world [1]. Aedes aegypti (Diptera: Culicidae) is a primary vector, which transmit dengue, as well as, yellow fever, chikungunya, and Zika [2]. Dengue, sometimes causing a potentially lethal complication called severe dengue, is considered the most important mosquito-borne viral disease in the world today with about half of the world's population now at risk [3]. Vector control using pesticides plays an important role in preventing vector-borne disease. Synthetic pesticides are the major and important tools in controlling vectors and, accordingly, preventing diseases transmission. Although insect populations develop resistance to certain synthetic pesticides, they can have adverse effects on non-targeted species, and natural materials have been considered as potential tools for pest management [4]. Search for mosquito-attractive semiochemicals has been a subject of interest in the last few decades. New compounds or odor blends are regularly proposed as lures for odor-baited traps [5].

There are a few reports in the literature where sheep were used as bait for rift valley fever virus (RVFV) vectors [6-8]. Studies by Tchouassi et al. [7,8] found that including sheep and other animal odors increases light trap catch of RVF virus mosquito vectors with U.S. Centers for Disease Control (CDC) light or $\mathrm{CO}_{2}$; and the odor may be the primary factor for mosquito attraction. According to Tchouassi et al. [8], aldehydes: heptanal, octanal, nonanal, decanal, present in RVF virus hosts' odors, including sheep, could play an important role in the attractancy of RVF mosquitoes. Yan at al. [9] studied the volatiles from Merino sheep wool samples collected by headspace SPME, and analyzed these by GC-MS-electroantennography; the samples containing octanal and nonanal possessed attractiveness to Lucilia cuprina (Diptera: Calliphoridae) flies.

The chemical composition of collected volatiles can be affected by various factors; e.g., Vasta et al. [10] using solid-phase microextraction (SPME) and GC-MS analysis of lamb fat samples, detected 6-methyl-2-heptanone and 2,5-dimethyl-4-hydroxy-3(2H)-furanone that were related to the time of grazing. Almela et al. [11] using SPME with fiber coatingdivinylbenzene-carboxen-polydimethylsiloxane and GC-MS methods, investigated aldehydes, alcohols, ketones, phenols, indole, and sulfur compounds, and found that the ewe's diet strongly affected the volatile compounds profile of the cooked meat. According to Burger et al. [12] bioassays during the lambing seasons confirmed the role of lamb odors in ewe-lamb recognition; they identified 133 volatile organic compounds in cranial wool of Döhne Merino lambs and found that the wool volatiles of twins are practically identical, but differ from those of other twins or non-twin lambs in the flock. The analysis of the headspace SPME volatile collection of a variety of scoured wool samples and greases using a carboxen-polydimethylsiloxane coated fiber, by a GC-MS and GC/pulsed flame photometric detector, showed the number of volatiles decreased after various stages of wool scouring [13].

Sheep wool is an agricultural waste produced by sheep breeding; it is a renewable, recyclable and environmentally friendly material, used in many fields and sectors, offering significant benefits for sustainability [14]. Wool fiber decomposition does not pose a risk to the environment and may even be used as a plant fertilizer [15]. Along with other advantages, sheep wool is attractive as an odor source because of its low cost.

In this work, we studied commercially available, stored sheep wool volatiles using various extraction and analysis techniques/methods, to identify the molecular composition of sheep wool odor, as a potential attractant for mosquitoes, and conducted bioassays 
to investigate the possibility of using this readily available and inexpensive material for mosquito management and surveillance. The molecular composition of sheep wool volatiles and, correspondingly, the potential activity against insects, could vary depending on the breed, species, age, diet, location, etc. Evaluation of the feasibility and reliability of this material, as a source of the desired volatiles, should be assessed taking into account all the variabilities, and is out of the scope of this work.

\section{Materials and Methods}

\subsection{Chemicals}

Ionol (Cas \#128-37-0, 2,6-di-tert-butyl-4-methylphenol (BHT)) was purchased from Sigma-Aldrich Co., (St. Louis, MO, USA). The thialdine (5,6-dihydro-2,4,6-trimethyl-4H1,3,5-dithiazine) was purchased from Enamine LLC (Monmouth Jct., Middlesex County, NJ, USA). Raw sheep wool (100\%), purchased via Amazon from Flowing River farm (Arcadia, WI, USA), was unwashed and unsorted, $4-5$ inch staple length, from Dorset Horn, North Country Cheviot and Île-de-France sheep, shorn at the farm in West Central Wisconsin. The sheep were raised in Wisconsin, had seasonal free range grazing, and were fed a well-balanced diet of assorted grains and forages.

\subsection{Extraction of Volatile Compounds}

\subsubsection{Hydrodistillation}

Sheep wool (160 g) was placed in a $3 \mathrm{~L}$ round bottom flask and water $(\sim 2000 \mathrm{~mL})$ was added to cover the wool material, and water $(\sim 2 \mathrm{~mL})$ was also added to the Clevenger unit (Figure 1). The distillation system was covered with aluminum foil and the temperature set to $100^{\circ} \mathrm{C}$ and the water-cooling system set on high stream. After $1 \mathrm{~h}$ of heating, the mixture in the flask started to boil and distillation started. The system was allowed to distill for $3 \mathrm{~h}$, and then heating was stopped to let the system cool $[16,17]$. Then, hydrosol $(5 \mathrm{~mL})$ was subjected to triplicate extractions with $2 \mathrm{~mL}$ of $n$-hexane. The condenser was washed with $n$-hexane $(2-3 \mathrm{~mL})$ and this hexane solution also was collected. Both solutions were combined, dried over anhydrous sulfate $\left(\mathrm{Na}_{2} \mathrm{SO}_{4}\right)$ and stored at $4{ }^{\circ} \mathrm{C}$ before analysis.

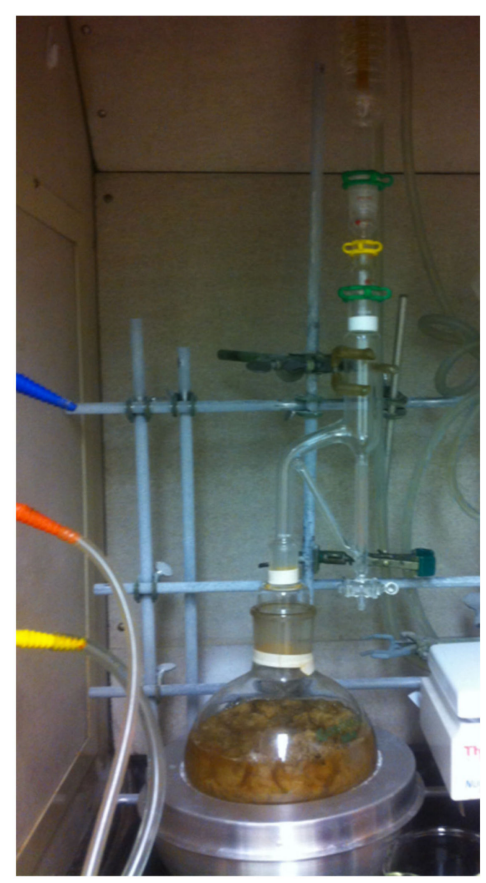

Figure 1. Hydrodistillation of sheep wool using the Clevenger type setup. 


\subsubsection{Dynamic Headspace Collection (DHS) by Hayesep-Q Polymer Adsorbent}

Sheep wool (100 g) was placed in a polyester Reynolds oven bag $(482 \mathrm{~mm} \times 596 \mathrm{~mm}$, Reynolds consumer products, Lake Forest, IL, USA), which prior to use was baked in the oven for $10 \mathrm{~h}$ at $80^{\circ} \mathrm{C}$. Volatiles were collected using the Hayesep-Q polymer $(0.5 \mathrm{~g})$ adsorbent (60-80 mesh, Hayes Separations, Inc.; Bandera, TX, USA) packed in a glass volatiles collection tube [18]. Prior to the experiment this collection tube was washed with hexane; the purity of this hexane-wash was verified by GC-MS, and the tube was baked in the oven at $50-60{ }^{\circ} \mathrm{C}$, for $5 \mathrm{~h}$. Then this tube was placed in a volatiles collection system (Figure 2) equipped with charcoal-filtered pressurized air entering the sealed container at $0.6 \mathrm{~L} / \mathrm{min}$. An outgoing tube from the oven bag with wool led to the volatile collection tube, and a vacuum pump with a vacuum gauge pulled air at $0.6 \mathrm{~L} / \mathrm{min}$ through the Hayesep-Q adsorbent material. Oven bag openings were sealed with black steel fold-back binder clips (medium, Business Source Products, Post Falls, ID, USA). Pressurized air and vacuum tubes (Figure 2) of corrugated fluorinated ethylene propylene (FEP) having $6.4 \times 5.6 \times 0.4 \mathrm{~mm}$ diameters and wall thickness, respectively, of $1.5 \mathrm{~m}$ length (Cole-Parmer North America, Vernon Hills, IL, USA) were fixed with Swagelok brass fittings (Swagelok, Jacksonville, FL, USA). The collection of volatiles continued for $6 \mathrm{~h}$, the collection tube was removed and then eluted with $200 \mu \mathrm{L}$ of hexane into a glass vial, and it was stored at $4{ }^{\circ} \mathrm{C}$ before analysis.

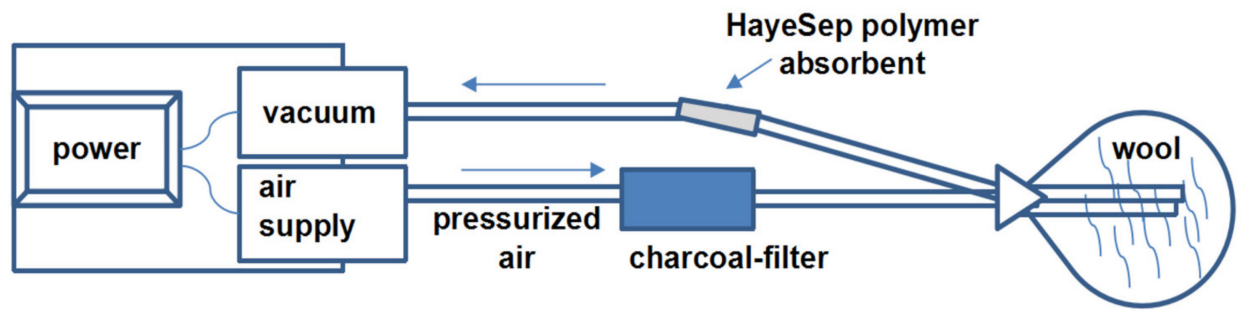

Figure 2. A schematic diagram of the dynamic headspace collection (DHS) system for collection of wool volatiles using Hayesep-Q polymer adsorbent.

\subsubsection{Headspace (HS) Collection by Solid-Phase Microextraction (HS-SPME)}

A manual SPME device (Supelco, Bellafonte, PA, USA) using different fibers composed of polydimethylsiloxane/divinylbenzene (PDMS/DVB), carboxen-polydimethylsiloxane (CAR/PDMS), and polydimethylsiloxane (PDMS) (Supelco Inc., Bellefonte, PA, USA) was used for extraction of the sheep wool volatiles $[19,20]$. Sheep wool $(0.2 \mathrm{mg})$ was transferred to a $15 \mathrm{~mL}$ vial and sealed with parafilm [21]. The extraction fiber was pushed through the parafilm layer for exposure to the headspace of the extract for $15 \mathrm{~min}$ at $40^{\circ} \mathrm{C}$. The blank collection with the parafilm was performed, as well, in the same conditions. The fiber was then inserted immediately into the injection port of the GC-MS for desorption of the adsorbed volatile compounds for analysis.

\subsection{Mass Spectrometry Analysis}

2.3.1. Gas Chromatography-Mass Spectrometry (GC-MS) Analysis with Closed Electron Ionization (CEI)

A $1 \mu \mathrm{L}$ aliquot from each extract was analyzed along with hexane blanks using a ThermoFinnigan DSQ (Thermo Fisher Scientific; Austin, TX, USA) gas chromatograph (GC) equipped with a DB- 5 column (Agilent; Santa Clara, CA, USA; $30 \mathrm{~m} \times 0.25 \mathrm{~mm}$ ID; $0.25 \mu \mathrm{m}$ film thickness). The GC oven temperature program was set at an initial temperature of $50{ }^{\circ} \mathrm{C}$ and held at that temperature for $10 \mathrm{~min}$ post-injection, ramped at $2{ }^{\circ} \mathrm{C} / \mathrm{min}$ to $180^{\circ} \mathrm{C}$, and then ramped at $10{ }^{\circ} \mathrm{C} / \mathrm{min}$ to $240{ }^{\circ} \mathrm{C}$. The mass analyzer was scanned at a rate of $0.5 \mathrm{sec}$ over a mass range of $\mathrm{m} / \mathrm{z} 35$ to 650 . The programmed temperature vaporizing (PTV) injection port was operated at $200{ }^{\circ} \mathrm{C}$ in split mode, the transfer line was set to $200{ }^{\circ} \mathrm{C}$, and the carrier gas was set to a constant flow of $1.5 \mathrm{~mL} / \mathrm{min}$. MS were recorded at $70 \mathrm{eV}$. The results of analysis are shown in Table 1. 
2.3.2. GC-Flame Ionization Detector (FID) and GC-MS with Electron Impact (EI) Ion Source

GC analysis was carried out using an Agilent 6890N GC system (SEM Ltd., Istanbul, Turkey) with the FID detector temperature set at $300{ }^{\circ} \mathrm{C}$. To obtain the same elution order with GC-MS, a simultaneous injection was undertaken using the same column and the same operational conditions. Relative percentage amounts of the separated compounds were calculated from FID chromatograms. The results of analysis are shown in Table 2.

The GC-MS analysis was carried out with an Agilent 5975 GC-MSD system (SEM Ltd., Istanbul, Turkey). An Innowax FSC column $(60 \mathrm{~m} \times 0.25 \mathrm{~mm}, 0.25 \mu \mathrm{m}$ film thickness, SEM Ltd., Istanbul, Turkey) was used with helium as carrier gas $(0.8 \mathrm{~mL} / \mathrm{min})$. The GC oven temperature program was set at an initial temperature of $60^{\circ} \mathrm{C}$ and held at that temperature for $10 \mathrm{~min}$ post-injection, ramped at $4{ }^{\circ} \mathrm{C} / \mathrm{min}$ to $220^{\circ} \mathrm{C}$, held at that temperature for $10 \mathrm{~min}$, and ramped at $1{ }^{\circ} \mathrm{C} / \mathrm{min}$ to $240{ }^{\circ} \mathrm{C}$. The injector temperature was $250{ }^{\circ} \mathrm{C}$. Mass spectra were recorded at $70 \mathrm{eV}$, where the mass range was from $m / z 35$ to 450 .

Compound Identification: Identification of the volatile components was carried out by comparison of their relative retention times with those of authentic samples or by comparison of their relative retention indices (RRI)/Kovats retention indices, to a series of $n$-alkanes [22]; compounds were analyzed under the same conditions, and compared with literature data. Non-isothermal Kovats retention indices were calculated using equation: $R R I_{x}=100 n+100\left(t_{x}-t_{n}\right) /\left(t_{n+1}-t_{n}\right)$, where $t_{n}$ and $t_{n+1}$ are retention times of the reference $n$-alkanes eluting before and after compound " $X$ "; $t_{x}$ is the retention time of

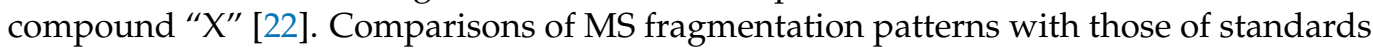
and a mass spectrum database search were performed using the Wiley GC-MS library (Wiley, New York, NY, USA), and the NIST library (US National Institute of Standards and Technology, Gaithersburg, MD, USA). Computer matching against commercial libraries (Wiley GC-MS Library, MassFinder 4 Library) [23,24] and in-house "Baser Library of Essential Oil Constituents" built up by genuine compounds and components of known oils (when identified by GC-FID/GC-MS), as well as MS literature data [25] were also used for the identification.

\subsection{Nuclear Magnetic Resonance (NMR) Analysis}

NMR analyses were conducted at the Center for Nuclear Magnetic Resonance Spectroscopy, University of Florida, Gainesville, FL, USA. NMR spectra were recorded in deuterated chloroform $\left(\mathrm{CDCl}_{3}\right.$, Sigma-Aldrich, St. Louis, $\mathrm{MO}$, USA) with TMS (tetramethylsilane $)$ as the internal standard for ${ }^{1} \mathrm{H}(500 \mathrm{MHz})$ and $\mathrm{CDCl}_{3}$ as the internal standard for ${ }^{13} \mathrm{C}(125 \mathrm{MHz})$. Hydrodistillate was subjected to the ${ }^{1} \mathrm{H}$ and ${ }^{13} \mathrm{C} \mathrm{NMR}$ analysis and compared to neat thialdine analysis results. The NMR shifts of a major compound in hydrodistillate and thialdine were identical.

Sheep hair hydrodistillate: off-white oil, ${ }^{1} \mathrm{H}$ NMR $\left(\mathrm{CDCl}_{3}\right) \delta 4.2(\mathrm{q}, J=6.9 \mathrm{~Hz}, 1 \mathrm{H})$, $4.07(\mathrm{q}, J=6.9 \mathrm{~Hz}, 1 \mathrm{H}), 1.48(\mathrm{~d}, J=7.0 \mathrm{~Hz}, 3 \mathrm{H}), 1.45(\mathrm{~d}, J=6.5 \mathrm{~Hz}, 6 \mathrm{H}) .{ }^{13} \mathrm{C} \mathrm{NMR}\left(\mathrm{CDCl}_{3}\right) \delta$ $61.2,44.1,22.7,21.9$.

\subsection{Bioassays}

The mosquito species used for testing was Ae. aegypti (Orlando strain, 1952) from colonies maintained at the Mosquito and Fly Research Unit at the US Department of Agriculture-Agricultural Research Service, Center for Medical, Agricultural, and Veterinary Entomology (USDA-ARS CMAVE) in Gainesville, FL, USA. Newly emerged mosquitoes were maintained on $10 \%$ sugar water and kept in laboratory cages at an ambient temperature of $28 \pm 1{ }^{\circ} \mathrm{C}$ and relative humidity $(\mathrm{RH})$ of 35-60\%. To investigate attractancy against adult female Ae. aegypti mosquitoes, raw sheep wool, the sheep wool hydrodistillate, and thialdine (the major component of hydrodistillate) were tested in the laboratory assays using glass tubes, and in the semi-field assays using the large screened outdoor cages. We could not perform bioassays with HS extracts because of their small quantities. 


\subsubsection{Glass Tube Attractancy Assays for Thialdine and Sheep Wool Hydrodistillate}

The sheep wool hydrodistillate and its major component, thialdine, were subjected to the attractancy assays against Ae. aegypti mosquitoes using the glass tubes (Figure 3, dimensions: $2.5 \mathrm{~cm}$ diameter and $12.5 \mathrm{~cm}$ length, TriKinetics Inc. Waltham, MA, USA), with two treatment caps (Corning Inc., New York, NY, USA) each of which held one filter paper (2.5 cm diameter, Sigma-Aldrich, St. Louis, MO, USA) [26]. Netting (purchased from http: / / www.michaels.com (accessed on 5 August 2018) was put between the end of glass tube and treated caps to prevent contact of treated paper by the mosquitoes. The glass tube sets were held vertically in a foam board made for the $50 \mathrm{~mL}$ centrifuge tubes. At the bottom cap, the filter paper was treated with $50 \mu \mathrm{L}$ of tested chemicals in acetone solution. The top cap was treated with $50 \mu \mathrm{L}$ of acetone as control. The tested chemicals were diluted at $0.01,0.1,1$, and $10 \mu \mathrm{g} / \mathrm{cm}^{2}$ concentrations. The treated filter paper was allowed $10 \mathrm{~min}$ to evaporate the solvent before inserting into the caps. Sixteen 3- to 7-day-old female mosquitoes, ice anesthetized, were induced into the glass tube, and allowed 15 min to recover before testing. A line was drawn in the middle of the tube and the proportion of mosquitoes on the chemical-treated side was recorded after 15, 30 and $60 \mathrm{~min}$. The positive control was $1 \mu \mathrm{g} / \mathrm{cm}^{2}$ of the attractant 1-octen-3-ol [27] and acetone treated paper on both caps was tested as solvent control. Attractancy was scored as a fraction of the mosquitoes on the chemically treated side at 15, 30, and $60 \mathrm{~min}$. Thus, an initial score with eight mosquitoes on either side of the midline is 0.5 and attractancy is expressed as a score $>0.5$ to 1.0 [26]. Each treatment was replicated three times. Co-applications of wool hydrodistillate at selected concentrations $\left(0.1,0.01 \mu \mathrm{g} / \mathrm{cm}^{2}\right)$ and $10 \mathrm{~mL}$ of $\mathrm{CO}_{2}$ were also tested and replicated three times to determine whether $\mathrm{CO}_{2}$ would enhance the attractancy to Ae. aegypti.

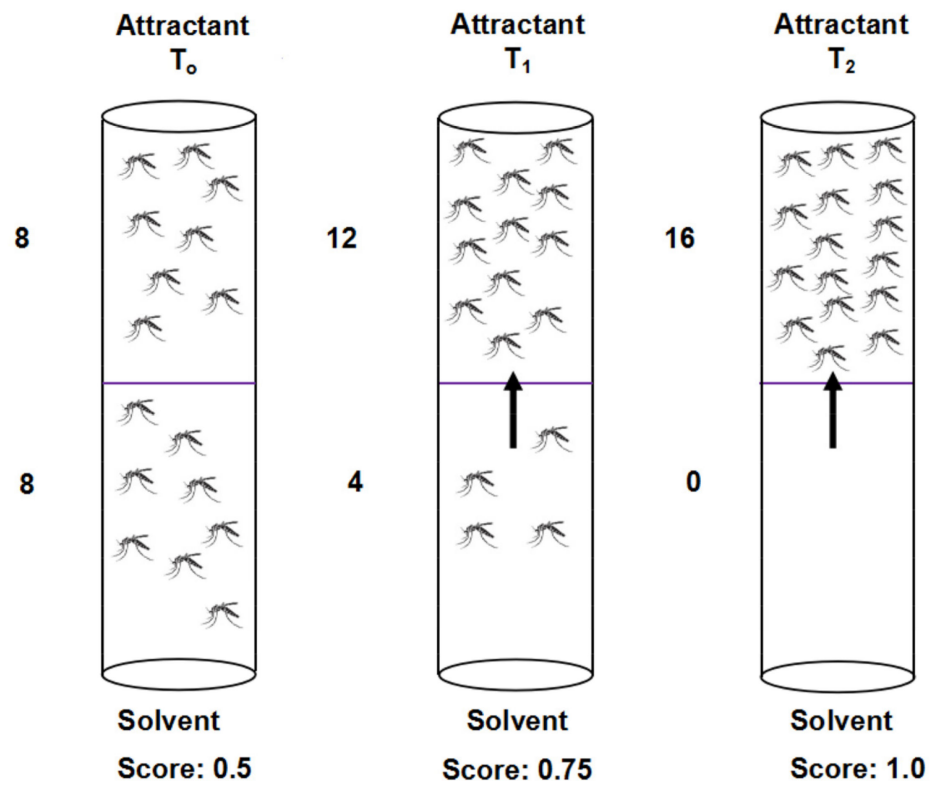

Figure 3. Attractancy assay for mosquitoes in glass tubes containing 16 females. Solvent or sheep hair volatiles were applied to filter papers and movement of mosquitoes was monitored over $1 \mathrm{~h}$. Scoring of attractancy was as indicated. $\mathrm{T}_{\mathrm{O}}, \mathrm{T}_{1}$, and $\mathrm{T}_{2}$, treatments.

2.5.2. Semi-Field Attractancy Assays with Sheep Wool Using Centers for Disease Control (CDC) Traps

Two hundred nulliparous 6- to 8-day-old female mosquitoes were transferred into mesh-covered paper cups (200 mL, Neptune Paper Cup Co., Newark, NJ, USA), and wet cotton placed on top of the mesh kept mosquitoes hydrated. Cups with mosquitoes were kept in a 16 L cooler box (Coleman Company, Inc. Chicago, IL, USA) until mosquitoes were released into large outdoor screened cages [28] (Figure 4). The cages were $69.25 \mathrm{~m}^{3}$ 
in volume, with dimensions of $3.05 \mathrm{~m}$ (front wall height), 2.44 (back wall height) $\times 6.5 \mathrm{~m}$ (length) $\times 4.2 \mathrm{~m}$ (width), and used in trap efficacy trials at USDA-ARS, CMAVE, Gainesville, FL, USA. The assays for attractancy were conducted using two cages, each equipped with a bait station containing a CDC trap (New Standard Miniature Incandescent Light Trap Model 1012, John W. Hock Company, Gainesville, FL, USA), and vortex unit (Vortex-Genie 2 Laboratory Mixer, Daigger Scientific, Inc., Vernon Hills, IL, USA), with no dry-ice, and the lights off (Figure 5). Sheep wool (20 g) was placed in a knee-high stocking (Leggs Everyday Knee Highs, Winston-Salem, NC, USA) and attached to the vortex platform head with a $7.6 \mathrm{~cm}$ diameter cover using black steel fold-back binder clips (large, Business Source Products, Post Falls, ID, USA). Vortexer was set at speed level 1 (600 rpm) with continuous hands-free operation. Adult female Ae. aegypti mosquitoes $(n=200)$ were used for each experimental cage. Before releasing mosquitoes into the cages, the mosquito traps were turned on and then, depending on the experimental setup, sheep wool in a stocking or only an empty stocking was attached to the vortex head (Figure 5), and the vortex was set on vibration or turned off. Every experiment was conducted in both cages simultaneously at least six times for each pair of baits. The baits were alternated for each subsequent test.

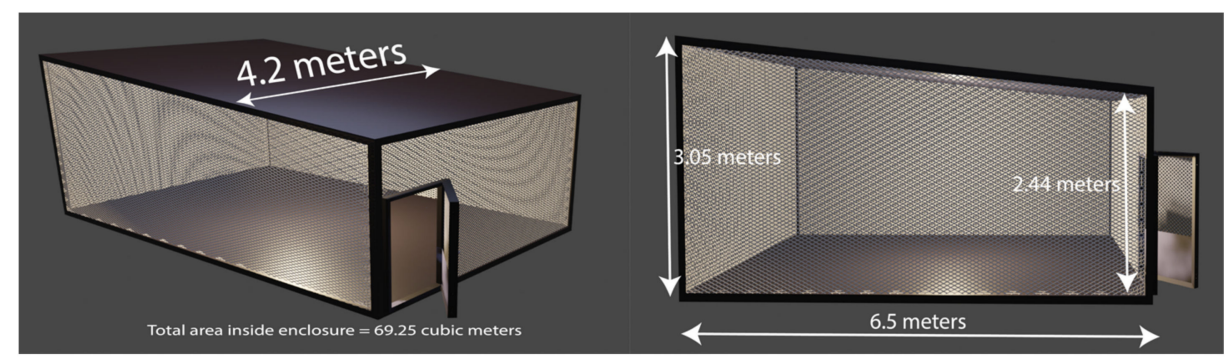

Figure 4. A diagram for the large screened outdoor cage. The bioassay setup is placed in the center of the cage.

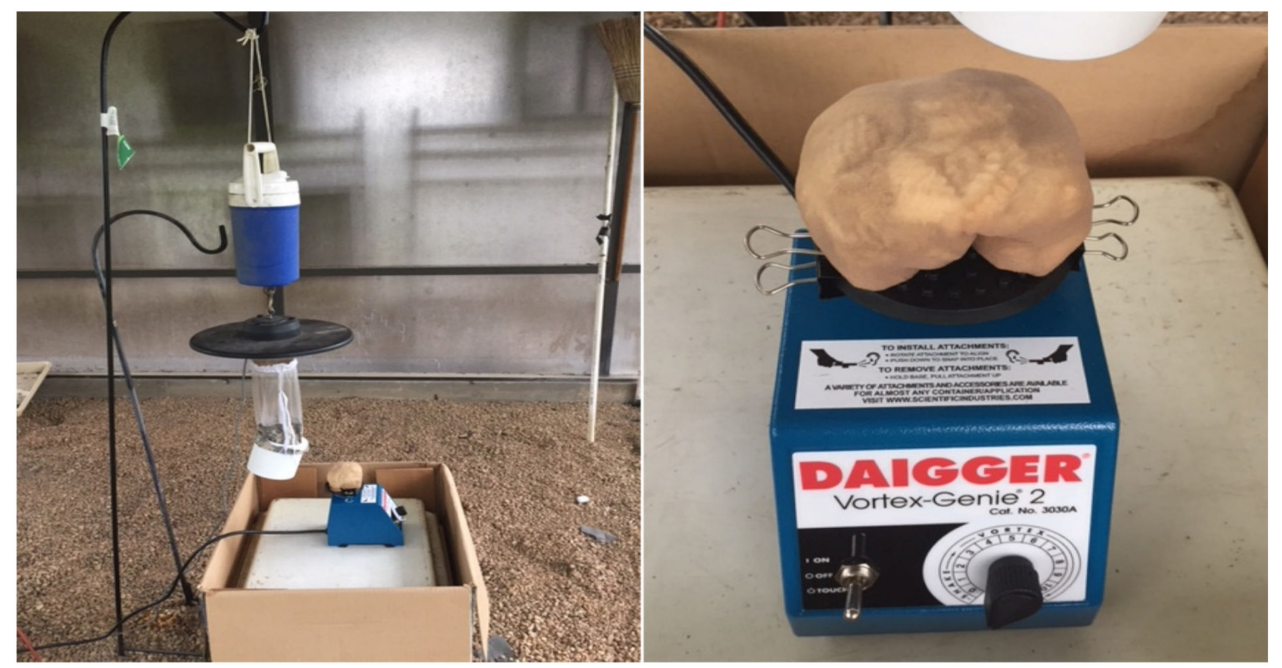

Figure 5. CDC trap and sheep wool placed in women's stocking attached to the Vortex platform head.

The following setups were used to determine the effects of various combinations of traps baited with/without wool, or with/without vibration. In setup/experiment A, one cage was equipped with wool which was compared to a cage without wool with the Vortex apparatus in both cages turned on to vibrate. In setup/experiment B, both cages were equipped with wool, but the Vortex vibrated in only one cage. For setup/experiment C, only one cage was baited with wool and the Vortex turned on to vibrate, which was compared against a cage with an empty stocking and the Vortex turned off. In setup/experiment D, 
the Vortex was turned on without wool as bait and compared to a cage containing wool as bait but the Vortex was turned off (no vibration).

Assays were started in the late afternoons at about 5-6 pm and lasted overnight. Next morning, after $\sim 16 \mathrm{~h}$, mosquitoes in the traps were collected, counted, and data analyzed. All experiments in the large outdoor cages were conducted in summer 2018. To compare attractiveness of the paired baits to each other the mean number of mosquitoes mean \pm SEM (standard error of the mean) for each bait, and the mean of the difference of these means for each pair \pm SED (standard error of difference) were used. Additionally, relative attractiveness (RA) was used to compare attractiveness of the paired baits to each other, similar to the glass tube assays. RA was expressed as mean RA \pm SEM, and reported as the number of mosquitoes collected from the trap of one bait, divided by the total number of mosquitoes collected from both (paired) traps together (the maximum attractive value for RA is 1 ; the efficacies of the paired baits are considered similar if RA $=0.5$ ).

\subsection{Statistical Analysis}

A two-tailed Student's $t$-test was used to analyze the results for glass tube attractancy assays. A two-tailed paired $t$-test was used to compare the collections of the pared baits in semi-field attractancy bioassays. All statistics were evaluated as significant when there was less than $5 \%$ chance of error $(p<0.05)$. Statistical analysis was conducted using RStudio [29] and Excel.

Table 1. Chemical composition of sheep wool hydrodistillate, and DHS volatile collection analyzed by gas chromatography-mass spectrometry (GC-MS).

\begin{tabular}{|c|c|c|c|c|c|}
\hline \multicolumn{2}{|r|}{ Compound } & \multicolumn{2}{|c|}{ Area \% } & \multirow[b]{2}{*}{ Identification } & \multirow{2}{*}{ References } \\
\hline RRI & Name & Hydrodistillate & DHS & & \\
\hline 960 & 6-methyl-2-heptanone ${ }^{b}$ & & 1.0 & MS & {$[10,30,31]$} \\
\hline 993 & 2-octanone ${ }^{a}$ & 0.9 & 0.7 & RRI, MS & [32] \\
\hline 1005 & octanal $^{\text {a }}$ & & 1.8 & RRI, MS & [8] \\
\hline 1078 & 1-octanol ${ }^{\mathrm{a}}$ & & 7.0 & RRI, MS & {$[3031]$} \\
\hline 1079 & $p$-cresol ${ }^{a}$ & 1.8 & & RRI, MS & \\
\hline 1100 & linalool & & 1.7 & RRI, MS & {$[30,33]$} \\
\hline 1106 & nonanal $^{\mathrm{a}}$ & & 15.3 & RRI, MS & [8] \\
\hline 1120 & $\begin{array}{l}\text { 3,5-dimethyl-1,2,4- } \\
\text { trithiolane (one of the } \\
\text { isomers) } a, b\end{array}$ & 2.1 & & MS & \\
\hline 1128 & $\begin{array}{l}\text { 3,5-dimethyl-1,2,4- } \\
\text { trithiolane (one of the } \\
\text { isomers) } a, b\end{array}$ & 3.7 & & MS & {$[30,31]$} \\
\hline 1196 & 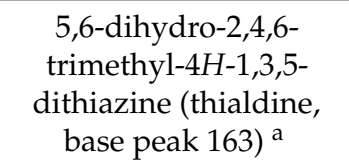 & 86.6 & & RRI, MS & \\
\hline 1200 & dodecane & & 5.8 & RRI, MS & [34] \\
\hline 1207 & decanal & & 1.1 & RRI, MS & [30] \\
\hline 1284 & bornyl acetate ${ }^{b}$ & & 1.4 & MS & {$[32,35]$} \\
\hline 1300 & tridecane $^{\text {a }}$ & & 16.2 & RRI, MS & {$[30,36]$} \\
\hline 1392 & longifolene $^{\mathrm{a}}$ & & 10.7 & RRI, MS & {$[34]$} \\
\hline 1399 & tetradecane $^{\mathrm{a}}$ & & 13.6 & RRI, MS & [30] \\
\hline
\end{tabular}


Table 1. Cont.

\begin{tabular}{cccccc}
\hline & Compound & \multicolumn{2}{c}{ Area \% } & & \multirow{2}{*}{ References } \\
\cline { 1 - 5 } RRI & Name & Hydrodistillate & DHS & Identification & \\
\hline 1404 & $\beta_{\text {-caryophyllene }}{ }^{\text {a }}$ & & 11.8 & RRI, MS & {$[35]$} \\
\hline 1498 & pentadecane $^{\text {a }}$ & & 5.1 & RRI, MS & {$[30,36]$} \\
\hline & Total & 95.1 & 93.2 & & \\
\hline
\end{tabular}

a Detected by both methods GC-MS and GC-FID/GC-MS in HS-Hayesep-Q collection, ${ }^{\mathrm{b}}$ Tentative identification from Wiley, DHS, dynamic headspace, RRI: Relative retention indices calculated against $n$-alkanes [22]. Identification method based on the relative retention indices (RRI) of authentic compounds on the DB- 5 column; MS, identified based on computer matching of the mass spectra with those of the Wiley and NIST libraries and literature data.

\section{Results}

\subsection{Extraction of Volatiles and Analysis by GC-MS and GC-FID/GC-MS}

Sheep wool volatiles were collected by hydrodistillation with the Clevenger apparatus, and also using HS collection methods, such as dynamic HS extraction by Hayesep-Q polymer adsorbent (Figures 1 and 2), and HS-SPMEs with three different types of fiber coating: PDMS/DVB, CAR/PDMS and PDMS. The chemical compositions of these extracts were identified by GC-MS and GC-FID/GC-MS spectrometry methods (Tables 1 and 2). Tables 1 and 2 show RRIs, compound names, composition (\%), and literature references [8,10-12,30-43] presenting these compounds in connection with the sheep products.

\subsubsection{GC-MS and GC-FID/GC-MS Analysis of Hydrodistillate}

According to the GC-MS and GC-FID/GC-MS methods, the major component of the hydrodistillate was thialdine ( $86 \%)$. Presence of thialdine was confirmed by comparing ${ }^{1} \mathrm{H}$ and ${ }^{13} \mathrm{C}$ NMR shifts of hydrodistillate to neat thialdine. Five compounds were detected in the hydrodistillate by GC-MS and 19 compounds by GC-FID/GC-MS (Tables 1 and 2). Two isomers of 3,5-dimethyl-1,2,4-trithiolane, and $p$-cresol (0.6-3.7\%) were identified by both methods.

\subsubsection{GC-MS and GC-FID/GC-MS Analysis of DHS Collection}

In the DHS extract with Hayesep-Q adsorbent, 14 compounds were identified by GCMS (Table 1). Alkanes were the major constituents ( 41\%): tridecane, tetradecane, dodecane, and pentadecane (listed by descending order); followed by the sesquiterpenes $(\sim 22 \%)$ : longifolene and $\beta$-caryophyllene; aldehydes ( 18\%): nonanal, octanal, and decanal; and one alcohol: 1-octanol ( 7\%). By GC-FID/GC-MS a total of 18 compounds were identified (Table 2) with alcohols as the major constituents ( 41\%): 2-ethyl hexanol, 1-octanol, 2hexanol, ionol, 3-hexanol, 1-heptanol and 1-nonanol; followed by alkanes ( 25\%): tridecane, pentadecane, tetradecane, hexadecane, octadecane and heptadecane; sesquiterpenes ( 13\%): longifolene and $\beta$-caryophyllene; one aldehyde: nonanal $(\sim 11 \%)$, and one ketone: 2hexanone $(\sim 8 \%)$. A total of 13 compounds in this collection were identified by both GC-MS and GC-FID/GC-MS methods (Tables 1 and 2). 
Table 2. Chemical composition of sheep wool hydrodistillate, DHS and HS-SPME volatile collections analyzed by gas chromatography-flame ionization detector (FID) combined with GC-MS.

\begin{tabular}{|c|c|c|c|c|c|c|c|c|}
\hline \multirow{4}{*}{ RRI } & \multirow{4}{*}{$\begin{array}{r}\text { Compound } \\
\text { Name }\end{array}$} & \multicolumn{5}{|c|}{ Area \% } & \multirow{4}{*}{ Identification } & \multirow{4}{*}{ References } \\
\hline & & \multicolumn{4}{|c|}{ Headspace } & & & \\
\hline & & \multirow{2}{*}{ Hydrodistillate } & & \multicolumn{3}{|c|}{ HS-SPME } & & \\
\hline & & & & PDMS/DVB & CAR/PDMS & PDMS & & \\
\hline 1087 & 2-hexanone ${ }^{b}$ & & 7.9 & & & & MS & [32] \\
\hline 1093 & hexanal & & & 9.0 & 16.9 & & RRI, MS & [37] \\
\hline 1155 & 1-butanol & & & trace & 4.8 & & RRI, MS & [11] \\
\hline 1194 & heptanal & & & 13.2 & 13.9 & & RRI, MS & {$[8,37]$} \\
\hline 1202 & 3-hexanol ${ }^{\text {b }}$ & & 2.7 & & & & MS & [37] \\
\hline 1212 & $\begin{array}{c}\text { isoamyl alcohol } \\
\text { (=3-methyl-1-butanol) }{ }^{b}\end{array}$ & & & 5.2 & 12.1 & & MS & - \\
\hline 1222 & 2-hexanol b & & 4.6 & & & & MS & [36] \\
\hline 1260 & 1-pentanol & & & 3.0 & 6.4 & & RRI, MS & [32] \\
\hline 1290 & 2-octanone ${ }^{a, b}$ & & & 1.6 & 1.0 & & MS & \\
\hline 1296 & octanal $^{\text {a }}$ & & & 5.0 & 3.2 & & RRI, MS & {$[8,37]$} \\
\hline 1300 & tridecane $^{\text {a }}$ & & 10.3 & & & & RRI, MS & [30] \\
\hline 1360 & 1-hexanol & & & 6.9 & 9.6 & & RRI, MS & [32] \\
\hline 1400 & tetradecane ${ }^{a}$ & & 3.1 & & & & RRI, MS & [36] \\
\hline 1400 & nonanal ${ }^{\text {a }}$ & & 10.6 & 8.0 & 1.9 & 6.6 & RRI, MS & {$[8,37]$} \\
\hline 1412 & $(E)$-2-hexenol ${ }^{\mathrm{b}}$ & & & 1.3 & 1.0 & & MS & - \\
\hline 1463 & 1-heptanol & & 2.4 & 3.3 & 3.4 & & RRI, MS & [35] \\
\hline 1496 & 2-ethyl hexanol a,b & & 21.0 & 3.9 & 3.2 & & MS & [10] \\
\hline 1496 & 2-decanone ${ }^{b}$ & 0.5 & & & & & MS & [32] \\
\hline 1500 & pentadecane $^{a}$ & 0.5 & 5.4 & & & & RRI, MS & {$[30,36]$} \\
\hline 1541 & benzaldehyde & & & 1.0 & 0.5 & & RRI, MS & [11] \\
\hline 1562 & 1-octanol ${ }^{\text {a }}$ & 0.4 & 5.7 & 2.2 & 0.9 & & RRI, MS & [36] \\
\hline 1583 & longifolene (=junipene) ${ }^{a, b}$ & & 6.9 & & & & MS & [34] \\
\hline 1600 & hexadecane & 0.3 & 3.0 & & & & RRI, MS & {$[30,36]$} \\
\hline 1604 & 2-undecanone ${ }^{\mathrm{b}}$ & 0.2 & & & & & MS & {$[32]$} \\
\hline 1612 & $\beta$-caryophyllene ${ }^{a}$ & & 6.2 & & & & RRI, MS & [35] \\
\hline 1614 & $\begin{array}{l}\text { 3,5-dimethyl-1,2,4-trithiolane } \\
\text { (one of the isomers) }{ }^{\mathrm{a}, \mathrm{b}}\end{array}$ & 0.6 & & & & & MS & {$[30,31]$} \\
\hline 1631 & $\begin{array}{c}\gamma \text {-pentalactone } \\
(=\gamma \text {-valerolactone })^{b}\end{array}$ & & & 1.1 & 0.7 & - & MS & [39] \\
\hline 1634 & $\begin{array}{l}\text { 3,5-dimethyl-1,2,4-trithiolane } \\
\text { (one of the isomers) }{ }^{a, b}\end{array}$ & 0.6 & & & & & MS & {$[30,31]$} \\
\hline 1664 & 1-nonanol & 0.9 & 1.3 & 0.5 & - & - & RRI, MS & [12] \\
\hline 1674 & 2-methylbutanoic acid ${ }^{\mathrm{b}}$ & & & 2.1 & 3.1 & 3.5 & MS & [37] \\
\hline 1700 & heptadecane & & 1.1 & & & & RRI, MS & {$[30,36]$} \\
\hline 1706 & $\alpha$-terpineol & & & 0.6 & - & - & RRI, MS & - \\
\hline 1762 & $\begin{array}{c}\text { 5,6-dihydro-2,4,6-trimethyl- } \\
4 H-1,3,5 \text {-dithiazine (thialdine, } \\
\text { base peak } 163)^{\text {a }}\end{array}$ & 85.1 & & & & & RRI, MS & {$[30,33]$} \\
\hline 1800 & octadecane & & 2.4 & & & & RRI, MS & {$[30,36]$} \\
\hline
\end{tabular}


Table 2. Cont.

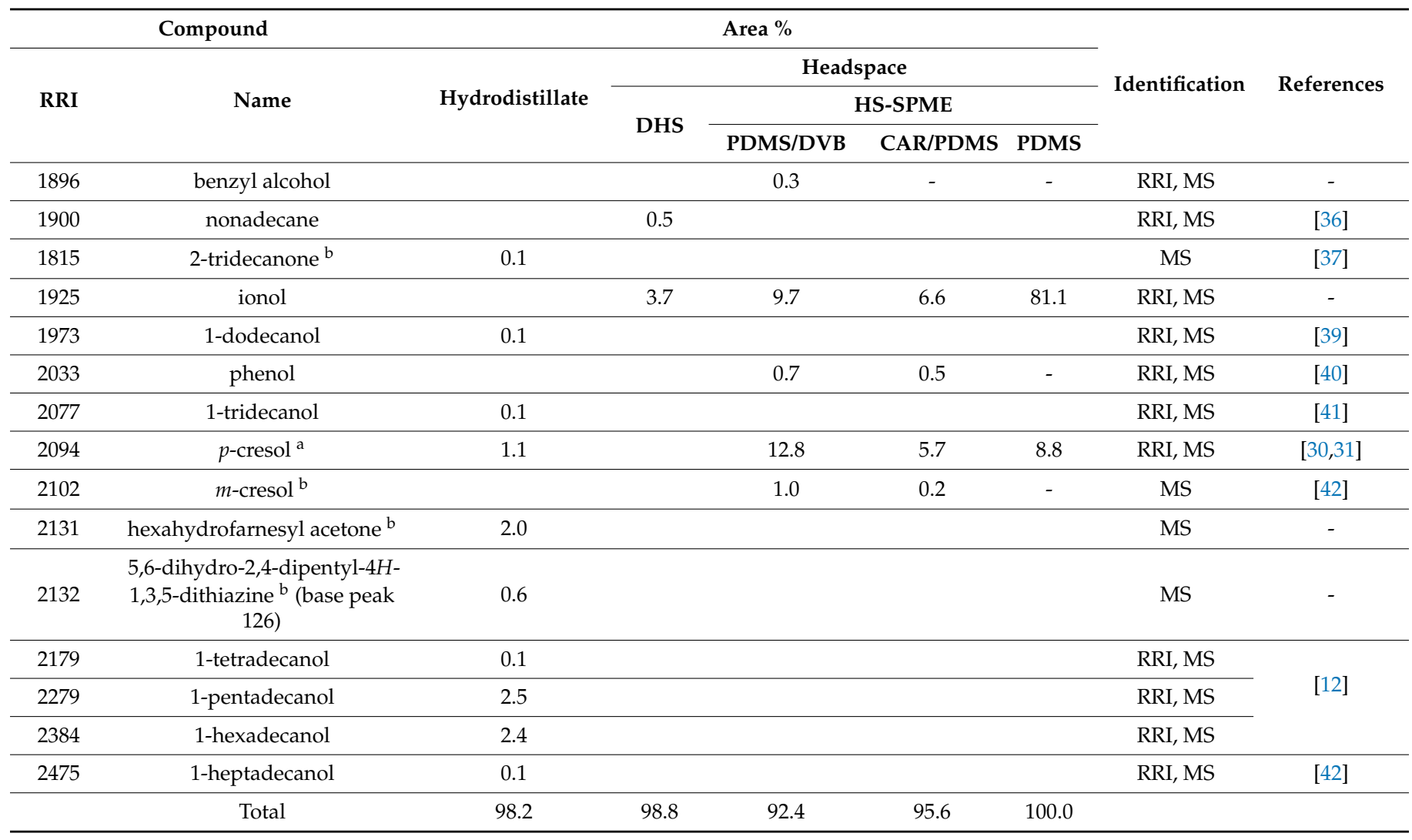

${ }^{a}$ Detected by both methods GC-MS and GC-FID in HS-Hayesep-Q collection, ${ }^{b}$ Tentative identification from Wiley, RRI: Relative retention indices calculated against $n$-alkanes, $\%$ calculated from FID data; Identification method based on the relative retention indices (RRI) of authentic compounds on the HP Innowax column; MS, identified based on computer matching of the mass spectra with those of the Wiley and MassFinder libraries and comparison with literature data, PDMS/DVB: precoated $65 \mu \mathrm{m}$-thick layer of polydimethylsiloxane-divinylbenzene, CAR/PDMS: precoated $75 \mu$ m-thick layer of carboxen-polydimethylsiloxane Red fiber: precoated PDMS: precoated $100 \mu \mathrm{m}$ thick layer of polydimethylsiloxane.

\subsubsection{GC-FID/GC-MS Analysis of HS-SPME Extracts by Three Different Fibers}

In the HS-SPME collection with PDMS/DVB fibers, 23 compounds were detected (Table 2). The extract consisted mostly of alcohols ( 49\%): $p$-cresol, ionol, 1-hexanol, isoamyl alcohol, 2-ethyl hexanol, 1-heptanol, 1-pentanol, 1-octanol, and $m$-cresol; aldehydes ( $36 \%)$ : heptanal, hexanal, nonanal, octanal, and benzaldehyde; also, 2-octanone $(1.6 \%), \gamma$ pentalactone $(1.1 \%)$, and 2-methylbutanoic acid (2.1\%). Almost the same major ingredients, 20 compounds, were detected in the extract by CAR/PDMS fibers; alcohols ( 56\%): isoamyl alcohol, 1-hexanol, ionol, 1-pentanol, $p$-cresol, 1-butanol, 1-heptanol, 2-ethyl hexanol, and (E)-2-hexenol; aldehydes ( 36\%): hexanal, heptanal, octanal, and nonanal; also, 2-octanone $(1.0 \%)$, and 2-methylbutanoic acid (3.1\%). Only four compounds were detected in the collection by PDMS fibers, with the major constituent ionol (81\%), followed by $p$-cresol $(8.8 \%)$, nonanal (6.6\%) and 2-methylbutanoic acid (3.5\%); All four of these compounds were detected in the extracts collected by PDMS/DVB and CAR/PDMS absorbents, as well.

\subsection{Bioassays and Data Analysis}

3.2.1. Attractant Activity of Sheep Wool Hydrodistillate and Thialdine in Glass Tubes

Glass tube assays were conducted using sheep wool hydrodistillate in comparison with its major component, thialdine (Figure 3, Table 3). A slight attractant effect was observed at $0.1 \mu \mathrm{g} / \mathrm{cm}^{2}$ of sheep wool hydrodistillate $(60 \mathrm{~min}$ ) or thialdine (15 min); little or no attractancy was observed on sheep wool hydrodistillate or thialdine at all other tested concentrations and times (Table 3), especially when compared to $1 \mu \mathrm{g} / \mathrm{cm}^{2}$ of 1 - 
octen-3-ol ( $0.75 \pm 0.02$ at $15 \mathrm{~min} ; 0.75 \pm 0.02$ at $30 \mathrm{~min} ; 0.81 \pm 0.05$ at $60 \mathrm{~min})$. Similarly, co-application with $10 \mathrm{~mL}$ of $\mathrm{CO}_{2}$ showed little attractancy at any time point to Ae. aegypti mosquitoes when tested at 0.1 and $0.01 \mu \mathrm{g} / \mathrm{cm}^{2}$ of sheep wool hydrodistillate. Thus, according to the assay results, the hydrodistillate and thialdine did not show any significant attractancy against female adult Ae. aegypti. It should be noted, that a slight repellent effect was observed at $10 \mu \mathrm{g} / \mathrm{cm}^{2}$ of sheep wool hydrodistillate at $15 \mathrm{~min}$; and at $1 \mu \mathrm{g} / \mathrm{cm}^{2}$ of thialdine at $30 \mathrm{~min}$.

Table 3. Proportion ( \pm SE) of adult female Ae. aegypti mosquitoes to sheep wool hydrodistillate and thialdine in glass tube assay.

\begin{tabular}{ccccccc}
\hline Concentrations & \multicolumn{2}{c}{ Sheep Wool Hydrodistillate } & \multicolumn{3}{c}{ Thialdine } \\
\hline$\left(\boldsymbol{\mu g} / \mathbf{c m}^{\mathbf{2}}\right)$ & $\mathbf{1 5} \mathbf{~}$ in & $\mathbf{3 0} \mathbf{~}$ in & $\mathbf{6 0} \mathbf{~}$ in & $\mathbf{1 5} \mathbf{~}$ in & $\mathbf{3 0} \mathbf{~ m i n}$ & $\mathbf{6 0} \mathbf{~}$ in \\
\hline 10 & $0.38 \pm 0.06$ & $0.48 \pm 0.04$ & $0.42 \pm 0.02$ & $0.46 \pm 0.04$ & $0.50 \pm 0.03$ & $0.48 \pm 0.02$ \\
1 & $0.44 \pm 0.06$ & $0.48 \pm 0.02$ & $0.48 \pm 0.02$ & $0.54 \pm 0.08$ & $0.38 \pm 0.04$ & $0.44 \pm 0.03$ \\
0.1 & $0.58 \pm 0.04$ & $0.58 \pm 0.04$ & $0.69 \pm 0.06$ & $0.62 \pm 0.06$ & $0.52 \pm 0.02$ & $0.58 \pm 0.02$ \\
0.01 & $0.58 \pm 0.04$ & $0.58 \pm 0.04$ & $0.48 \pm 0.05$ & $0.50 \pm 0.03$ & $0.50 \pm 0.06$ & $0.50 \pm 0.04$ \\
Solvent control & $0.52 \pm 0.02$ & $0.54 \pm 0.02$ & $0.50 \pm 0.03$ & $0.52 \pm 0.02$ & $0.54 \pm 0.02$ & $0.48 \pm 0.02$ \\
\hline
\end{tabular}

$\mathrm{SE}$, standard error.

\subsubsection{The Attractant Activity of Sheep Wool Using Semi-Field Bioassays}

A two-tailed paired $t$-test was used to compare the efficacies of the baits and determine the statistical significance of the differences within the pairs. The mean $( \pm$ SEM) number of mosquitoes for each bait and the mean of the difference of these means ( \pm SED) for each pair are presented in Table 4 . The difference was statistically very significant $(60.29 \pm 15.30)$ when bait "vibration + wool" was compared to bait "none" (setup C) (Figures 4 and 5). The differences between the paired baits "vibration + wool" vs. "vibration" $35.25 \pm 8.85$ (setup A), and "vibration + wool" vs. "wool" $29.67 \pm 7.62$ (setup B) were significant, as well. There was no significant difference between the efficacies of captures by baits "vibration" vs. "wool” $20.83 \pm 20.82(\mathrm{D})$, Table 4.

Table 4. Summary of paired $t$-tests for comparison of differences between the mean amounts of mosquitoes collected in the paired traps in setups A, B, C, and D in semi-field assay.

\begin{tabular}{|c|c|c|c|c|c|c|c|}
\hline Setups & Paired Bates & Mean \pm SEM & $\begin{array}{c}\text { Mean of } \\
\text { Difference } \pm \text { SED }\end{array}$ & $\begin{array}{l}95 \% \text { CI of } \\
\text { Difference }\end{array}$ & $\begin{array}{c}\mathrm{t} \text {-Value } \\
(t \text {-Critical })\end{array}$ & $\begin{array}{l}n \\
\text { df }\end{array}$ & $\begin{array}{l}p \text {-Value } \\
\text { Two-Tail }\end{array}$ \\
\hline \multirow{2}{*}{ A } & vibration + wool & $126.13 \pm 11.91$ & \multirow{2}{*}{$35.25 \pm 8.85$} & \multirow{2}{*}{$14.31-56.19$} & \multirow{2}{*}{$3.98(2.36)$} & \multirow{2}{*}{8,7} & \multirow{2}{*}{0.005} \\
\hline & vibration & $90.88 \pm 11.13$ & & & & & \\
\hline \multirow{2}{*}{ B } & vibration + wool & $113.5 \pm 12.82$ & \multirow{2}{*}{$29.67 \pm 7.62$} & \multirow{2}{*}{$10.08-49.25$} & \multirow{2}{*}{$3.90(2.57)$} & \multirow{2}{*}{6,5} & \multirow{2}{*}{0.012} \\
\hline & wool & $83.83 \pm 15.39$ & & & & & \\
\hline \multirow{2}{*}{$\mathrm{C}$} & vibration + wool & $98.29 \pm 19.56$ & \multirow{2}{*}{$60.29 \pm 15.30$} & \multirow{2}{*}{$22.86-97.72$} & \multirow{2}{*}{$3.94(2.45)$} & \multirow{2}{*}{7,6} & \multirow{2}{*}{0.008} \\
\hline & none & $38.00 \pm 6.70$ & & & & & \\
\hline $\mathrm{D}$ & $\begin{array}{l}\text { vibration } \\
\text { wool }\end{array}$ & $\begin{array}{l}151.67 \pm 13.05 \\
130.83 \pm 13.87\end{array}$ & $20.83 \pm 20.82$ & $(-2.09)-43.75$ & $2.34(2.57)$ & 6,5 & 0.067 \\
\hline
\end{tabular}

SEM, standard error of the mean, SED, standard error of difference, CI, confidence interval, $n$, number of paired treatments.

Relative attractiveness for paired baits "vibration + wool" vs. "none" was $0.70 \pm 0.04$ (setup C). RAs for paired baits "vibration + wool" vs. "vibration", and "vibration + wool" vs. "wool" were almost identical, $0.58 \pm 0.02$, and $0.58 \pm 0.03$, correspondingly (setups A, and B).

These results show that vibrated sheep wool is a better attractant than the baits with only wool or vibrated bait but without wool. Baits "vibration" vs. "wool" seem to have almost similar effects. 


\section{Discussion}

\subsection{Comparison of the Extraction Techniques for Chemical Analysis}

The chemical composition of the sheep wool extracts varied across the collections depending on the extraction methods or types of fibers used: e.g., the hydrodistillate mainly contained thialdine, while it was not detected in HS-volatile collections. Thialdine previously was reported in the volatiles of roasted lamb fat [30,33], and preserved duck eggs [44]. Thialdine is formed during cooking and is most familiar as a flavor component of foods [45]. Investigation using X-ray diffraction data showed that thialdine has an all cis-configuration [46].

3,5-Dimethyl-1,2,4-trithiolane isomers were also characteristic of hydrodistillate and detected by both MS methods. Hexahydrofarnesyl acetone, and alcohols: 1- do-, tri-, tetra-, penta-, hexa-, and hepta-decanols, with a few other trace compounds were detected in hydrodistillate by GC-FID/GC-MS (Tables 1 and 2). GC-FID/GC-MS also found $p$-Cresol, hexadecane, pentadecane, 1-octanol, and 1-nonanol in hydrodistillate, and in at least one of the HS collections.

For DHS extract, almost all compounds identified by GC-MS were detected by GCFID/GC-MS, as well, except for linalool, dodecane, and decanal; while, with GC-FID/GCMS, additionally, 2-hexanone, 3-hexanol, 2-hexanol, 1-heptanol, hexadecane, 1-nonanol, heptadecane, octadecane, nonadecane and ionol were detected (Table 2).

Nonanal was the only compound found in all HS collections, detected by both MS methods. 1-Heptanol, 2-ethyl hexanol, and 1-octanol were also found in all HS collections except for SPME by PDMS. The volatiles collected using HS-SPME by PDMS/DVB, and CAR/PDMS, such as hexanal, 1-butanol, heptanal, isoamyl alcohol, 1-pentanol, 1-hexanol, (E)-2-hexenol, benzaldehyde, $\gamma$-pentalactone, 2-methylbutanoic acid, phenol, $m$-cresol, were not detected in DHS collection.

While the major component of wool hydrodistillate was thialdine, the major components for HS-SPME (by PDMS/DVB, CAR/PDMS, and PDMS fibers), and DHS (by Hayesep-Q fiber) collections of row wool were alcohols, aldehydes, alkanes and sesquiterpenes. The HS extracts did not contain thialdine, since this compound is formed during cooking (in this case, hydrodistillation) [45].

It is known that the composition of extracts could greatly depend on the extraction methods used, e.g., in HS extracts the volatile collections vary according to the type of fiber coating, and its ability to absorb/adsorb volatiles; also, desorption techniques (e.g., with solvent, thermal) can play an important role on the composition of the extract. HS SPME and DHS are convenient methods for determination of volatile compounds, and both require much smaller sample amounts compared to hydrodistillation; also, HS SPME and DHS methods require no solvents to absorb/adsorb volatiles, and this is an important advantage. Hydrodistillation can extract large amounts of semi-volatile constituents, most of them might not be in sufficient amounts for headspace collection; hydrodistillation uses water steam, and sometimes this can induce chemical reactions (e.g., thialdine formation).

Furthermore, when concentration of the extracted volatiles is very low, the spectrometer cannot detect compounds at concentrations that are below its detection levels. The wool material we used in this study was stored and, accordingly, the volatiles emission might not be as intensive as for fresh material. Accordingly, the volatiles composition varied greatly not only in terms of the extraction techniques used, but also by detection methods applied. Although the two methods, GC-MS and GC-FID/GC-MS, have advantages and disadvantages [47], both analytical approaches provided important insights. Thus, according to the analytical results (Tables 1 and 2), none of the methods were ideal for extraction, or detection of the volatiles, rather they complemented each other.

A total of 52 compounds were detected (Tables 1 and 2), of which seven compounds: isoamyl alcohol, (E)-2-hexenol, $\alpha$-terpineol, benzyl alcohol, ionol, hexahydrofarnesyl acetone, and 5,6-dihydro-2,4-dipentyl-4H-1,3,5-dithiazine were not reported previously in sheep products to the best of our knowledge. 


\subsection{Extracted Sheep Wool Volatiles and Their Activity against Mosquitoes}

Most of the volatile compounds we identified from sheep wool (Tables 1 and 2) were found previously in sheep-derived products and reported in the literature $[8,10-12,30-43]$. This set includes those aldehydes, potent attractants for RVFV mosquito vectors-heptanal, octanal, nonanal, decanal [8]. Among the semiochemicals used by mosquitoes during mating, oviposition, host-seeking, and/or sugar feeding are the compounds: 2-ethyl hexanol, $p$-cresol, hexanal, heptanal, octanal, nonanal, decanal, benzaldehyde, $\beta$-caryophyllene, and phenol [8,48-59]. Various insects including mosquitoes were attracted to dodecane [59]. 2Hexanone and 1-butanol showed mosquito attractant activity [60], and 2-octanone showed attractancy against Culex pipiens (Diptera: Culicidae) [61]. Octanal was attractive to Ae. aegypti mosquitoes [62] and octanal, nonanal, and decanal, in olfactometer trials, interfered with the attraction of species to a host [63]. Torres-Estrada et al. (2005) identified several compounds from plant extracts, including longifolene and caryophyllene, as attractants for oviposition of Anopeles albimanus (Diptera: Culicidae) [64]. An increased attraction of $A n$. stephensi (Diptera: Culicidae) was observed for 3-methylbutanoic acid, 2-methylbutanoic acid, hexanoic acid, and tridecane [65]. Hexadecane along with a group of other compounds significantly reduced trap catches of An. arabiensis (Diptera: Culicidae) compared to a negative control [66].

$\beta$-Caryophyllene and decanal elicited antennal responses from An. arabiensis during gas chromatography coupled to electroantennographic detection (GC-EAD) experiments [48]. Electroantennograms recorded with Toxorhynchites moctezuma (Diptera: Culicidae) and T. amboinensis (Diptera: Culicidae) mosquitoes for phenol, $m$-cresol, $p$-cresol (along with several other compounds) showed oviposition attractancy [67]. Hexanal showed EAD-activity against An. gambiae (Diptera: Culicidae) [51].

The study conducted by Robinson et al. [53] revealed an increase in attraction of An. gambiae towards a synthetic blend containing heptanal, nonanal and, octanal. The compounds 3-hexanol, 1-hexanol, and 1-pentanol activate $\mathrm{CO}_{2}$-sensitive olfactory neurons in Ae. aegypti and An. gambiae [68]. Higher amounts of 2-methylbutanoic acid and octanal, along with two other compounds, were associated with individuals that were highly attractive to An. gambiae [69]. Isoamyl alcohol was among the six most promising candidate oviposition semiochemicals (An. gambiae) out of 50 identified volatiles that were emitted from the headspace of the most attractive bacteria isolates [70].

According to these literature studies [8,10-12,30-43,48-70], many constituents of sheep wool (Tables 1 and 2), showed attractant activity against mosquitoes. Aldehydes that were active against mosquitoes: hexanal, heptanal, octanal, nonanal, decanal, and benzaldehyde $[8,10-12,30-43,48-58,62,63,69]$ were present in a DHS extract of sheep wool at $\sim 18.2 \%$ (nonanal, octanal, and decanal), and $\sim 10.6 \%$ (nonanal), detected by GC-MS, and GCFID/GC-MS, correspondingly; in HS-SPME collections, by PDMS/DVB, and CAR/PDMS they were present at $\sim 36.2 \%$ and $36.4 \%$ (heptanal, hexanal, nonanal, octanal, and benzaldehyde), correspondingly, and by PDMS 6.6\% (nonanal), detected by GC-FID/GC-MS (Tables 1 and 2).

Alcohols that were active against mosquitoes: 1-butanol, $m$-cresol, $p$-cresol, 1-hexanol, 3-hexanol, 2-ethyl hexanol, isoamyl alcohol, phenol, 1-pentanol [60,67,68,70], were present in hydrodistillate at $\sim 1.8 \%$ and $\sim 1.1 \%$ ( $p$-cresol), detected by GC-MS, and GC-FID/GC-MS, correspondingly; in DHS extract they were at $23.7 \%$ (2-ethyl hexanol, and 3-hexanol), and, in HS-SPME collections, by PDMS/DVB, CAR/PDMS, and PDMS at $32.8 \%$ ( $p$-cresol, 1-hexanol, isoamyl alcohol, 2-ethyl hexanol, 1-pentanol, and $m$-cresol), $42.0 \%$ (isoamyl alcohol, 1-hexanol, 1-pentanol, $p$-cresol, 1-butanol, 2-ethyl hexanol, and $m$-cresol), and $\sim 8.8 \%$ ( $p$-cresol), correspondingly, detected by GC-FID/GC-MS (Tables 1 and 2).

Sesquiterpenes that were active against mosquitoes: $\beta$-caryophyllene, longifolene, [48,70], were present in DHS extract at $\sim 22.5 \%$, and $\sim 13.1 \%$ ( $\beta$-caryophyllene, longifolene) detected by GC-MS, and GC-FID/GC-MS, correspondingly (Tables 1 and 2).

Alkanes that were active against mosquitoes: dodecane, tridecane, hexadecane $[59,65,66]$, were present in DHS extract at $\sim 22.0 \%$ (tridecane, and dodecane), and $~ 13.3 \%$ (tridecane, 
and hexadecane) detected by GC-MS, and GC-FID/GC-MS, correspondingly; in hydrodistillate hexadecane was detected at $\sim 0.3 \%$ by GC-FID/GC-MS (Tables 1 and 2).

Ketones that were active against mosquitoes: 2-hexanone, and 2-octanone [60,61], were present in hydrodistillate and DHS extract at $\sim 0.9 \%$, and $0.7 \%$ (2-octanone), correspondingly, detected by GC-MS; and detected by GC-FID/GC-MS, in DHS extract they were present at $77.9 \%$ (2-hexanone), and, in HS-SPME collections, by PDMS/DVB and CAR/PDMS at $\sim 1.6 \%$, and $\sim 1.0 \%$ (2-octanone), correspondingly, (Tables 1 and 2 ).

2-Methylbutanoic acid which showed activity against mosquitoes [65,69], was present in HS-SPME collections by PDMS/DVB, CAR/PDMS, and PDMS at 2.1\%, 3.1\%, and 3.5\%, correspondingly, detected by GC-FID/GC-MS (Table 2).

\subsection{Bioassays}

While the sheep wool hydrodistillate and its major component thialdine did not show any significant attractant activity against adult female Ae. aegypti mosquitoes in glass tube bioassays, the baits with dynamic (vibrated) raw sheep wool were attractive to $A e$. aegypti compared to the static baits, or dynamic baits but without wool. Baits with sheep wool, dynamic or static, could both be sources of volatiles, but under static conditions the odor emanating from wool may not be strong enough to stimulate the mosquito's olfactory sensors. When vibrated, the volatile compounds, most probably, are released more intensively from the wool fiber, and the released volatiles, as potential attractants, increase mosquito capture. The attractant activity of vibrated raw sheep wool could be attributed to the volatile molecules from the HS extracts containing significant amounts of those aldehydes, alcohols, sesquiterpenes, alkanes, ketones, or 2-methylbutanoic acid (Tables 1 and 2) that were identified as active against mosquitoes according to the literature reports $[8,10-12,30-43,48-70]$. On the contrary, in sheep wool hydrodistillate these compounds were present only in small amounts: e.g., p-cresol, detected by GC-MS and GC-FID/GC-MS, was present at < 2\%, 2-octanone, detected by GC-MS, was present at $\sim 0.9 \%$, and hexadecane, detected by GC-FID/GC-MS, was present at $\sim 0.3 \%$. The major component of the hydrodistillate, thialdine, which is product of cooking [45], was not attractive to adult female Ae. aegypti, according to glass tube bioassays.

In semi-field bioassays with raw sheep wool, the following factors could be involved affecting mosquito attraction: chemical (volatiles released by wool) and visual (vibrating Vortex) signals. It should be noted that sound could also influence mosquito behavior, according to Dou et al. [71], who studied Ae. aegypti and An. gambiae mosquitoes responses to sound stimulus; in our case, sound from the vibrating Vortex.

Thus, the attraction of adult female Ae. aegypti to vibrating sheep wool may have been a combination of the effects of olfactory, visual, and, also, acoustic cues; of which the olfactory cues should be most important as, according to a recent study on adult female Ae. aegypti by Vinauger et al. [72], olfactory cues seem to play a greater role in attracting mosquitoes to the host than their visual cues.

According to Tchouassi et al. [7], during storage the hair could lose volatile compounds over time compared to the dynamic production from live animals, and in our semi-field experiments, we tried to create the dynamic conditions by vibrating sheep wool, which, we assume, intensified the process of releasing volatiles, that appear to be still present in stored sheep wool, and this intensive emission of volatiles considerably increased mosquito collection in the traps.

\section{Conclusions}

In this work, we studied the chemical composition of stored sheep wool volatiles and the attractancy of wool for adult female Ae. aegypti mosquitoes. The wool extracts were obtained by hydrodistillation and the various HS extraction methods. A total of 52 compounds were still present in stored wool detected by GC-MS and GC-FID/GC-MS methods. Seven compounds were not reported previously in the sheep products to the best of our knowledge. These compounds were collected by various extraction methods, 
and were detected with one and/or another spectrometry techniques, so the methods complemented each other. The hydrodistillate mainly contained thialdine detected by both spectrometry techniques. The main components of DHS volatile extract identified by GC-MS were alkanes, and, by GC-FID/GC-MS were alcohols. The main components of HS-SPME extracts identified by GC-FID/GC-MS in PDMS/DVB, and C/PDMS collections were alcohols and aldehydes, while ionol was the main component when PDMS was used as absorbent. Many of the detected compounds were previously reported as having some level of attractancy against mosquitoes. The sheep wool hydrodistillate and its main component thialdine did not show any significant attractant activity in the glass tube tests. Semi-field bioassays in the outdoor large screened cages equipped with the CDC traps and Vortex apparatus revealed the bait with vibrated sheep wool was a significantly better attractant (RA $~ 0.70$ ) than the bait with no wool and no vibration. In baits with vibrated sheep wool, attraction to mosquitoes could be influenced by combination of olfactory, and visual cues (also, sound from vibrated Vortex might influence mosquito behavior). Of these, olfactory signals seem to be the most important. We assume that under dynamic conditions stored sheep wool more intensively releases volatiles while the emission is limited when wool is not moving and this approach could be an option for increasing the efficacy of mosquito capture in bait systems. In the future, on the basis of identified potential attractants from the raw sheep wool volatiles, various blends could be tested for attractancy against mosquitoes, in order to find new active volatile combinations that increase mosquito capture in the traps. Research on raw sheep wool could be extended to test sheep wool baits with $\mathrm{CO}_{2}$, and light; and experiments could be conducted with other natural materials. Sheep wool is an easily available, affordable, and environmentally friendly product that should make this material attractive for use in mosquito management and surveillance.

Author Contributions: Conceptualization, M.T., N.T. and D.L.K.; methodology, M.T., N.T. and D.L.K.; investigation, M.T., N.T., D.L.K., B.D. and L.Y.; resources, U.R.B., K.J.L. and J.R.B.; data analysis, M.T.; writing—original draft preparation, M.T. and N.T.; writing—review and editing, U.R.B., K.J.L., D.L.K., J.R.B. All authors have read and agreed to the published version of the manuscript.

Funding: This work was supported by the Deployed War-Fighter Protection Research Program and funded by the United States Department of Defense through the Armed Forces Pest Management Board [Agreement 60-0208-4-001 and under USDA Specific Cooperative Agreements 58-0208-0-068 and 58-0208-5-001].

Institutional Review Board Statement: Not applicable.

Informed Consent Statement: Not applicable.

Data Availability Statement: The data presented in this study are available on request from the corresponding author.

Acknowledgments: We thank Sandra A. Allan (USDA-Agricultural Research Service-Center for Medical, Agricultural, and Veterinary Entomology) for support with HS collection technique; Center for NMR Spectroscopy, University of Florida, Gainesville, FL, USA.

Conflicts of Interest: The authors declare no conflict of interest. The funders had no role in the design of the study; in the collection, analyses, or interpretation of data; in the writing of the manuscript, or in the decision to publish the results.

\section{References}

1. Pant, C. Vector-borne diseases of man and their socio-economic impact. Int. J. Trop. Insect Sci. 1987, 8, 655-664. [CrossRef]

2. European Centre for Disease Prevention and Control. Aedes aegypti-Factsheet for Experts. Available online: https://www.ecdc. europa.eu/en/disease-vectors/facts/mosquito-factsheets/aedes-aegypti (accessed on 31 January 2022).

3. WHO. 2019. Available online: https://www.who.int/news-room/questions-and-answers/item/dengue-and-severe-dengue (accessed on 31 January 2022). 
4. Amala, K.; Karthi, S.; Ganesan, R.; Radhakrishnan, N.; Srinivasan, K.; Mostafa, A.E.; Al-Ghamdi, A.A.; Alkahtani, J.; Elshikh, M.S.; Senthil-Nathan, S.; et al. Bioefficacy of Epaltes divaricata (L.) n-Hexane Extracts and Their Major Metabolites against the Lepidopteran Pests Spodoptera litura (fab.) and Dengue Mosquito Aedes aegypti (Linn.). Molecules 2021, 26, 3695. [CrossRef] [PubMed]

5. Dormont, L.; Mulatier, M.; Carrasco, D.; Cohuet, A. Mosquito Attractants. J. Chem. Ecol. 2021, 47, 351-393. [CrossRef] [PubMed]

6. Chevalier, V.; Mondet, B.; Diaïté, A.; Lancelot, R.; Fall, A.G.; Ponçon, N. Exposure of sheep to mosquito bites: Possible consequences for the transmission risk of Rift Valley Fever in Senegal. Med. Vet. Ėntomol. 2004, 18, 247-255. [CrossRef] [PubMed]

7. Tchouassi, D.P.; Sang, R.; Sole, C.L.; Bastos, A.D.S.; Mithoefer, K.; Torto, B. Sheep Skin Odor Improves Trap Captures of Mosquito. PLoS Negl. Trop. Dis. 2012, 6, e1879. [CrossRef] [PubMed]

8. Tchouassi, D.P.; Sang, R.; Sole, C.L.; Bastos, A.D.S.; Teal, P.E.A.; Borgemeister, C.; Torto, B. Common Host-Derived Chemicals Increase Catches of Disease-Transmitting Mosquitoes and Can Improve Early Warning Systems for Rift Valley Fever Virus. PLoS Negl. Trop. Dis. 2013, 7, e2007. [CrossRef]

9. Yan, G.; Liu, S.; Schlink, A.C.; Flematti, G.R.; Brodie, B.S.; Bohman, B.; Greeff, J.C.; Vercoe, P.E.; Hu, J.; Martin, G.B. Volatiles from Merino fleece evoke antennal and behavioural responses in the Australian sheep blow fly Lucilia cuprina. Med. Vet. Èntomol. 2019, 33, 491-497. [CrossRef]

10. Vasta, V.; Ventura, V.; Luciano, G.; Andronico, V.; Pagano, R.I.; Scerra, M.; Biondi, L.; Avondo, M.; Priolo, A. The volatile compounds in lamb fat are affected by the time of grazing. Meat Sci. 2012, 90, 451-456. [CrossRef]

11. Almela, E.; Jordán, M.J.; Martínez, C.; Sotomayor, J.A.; Bedia, M.; Bañón, S. Ewe's Diet (Pasture vs Grain-Based Feed) Affects Volatile Profile of Cooked Meat from Light Lamb. J. Agric. Food Chem. 2010, 58, 9641-9646. [CrossRef]

12. Burger, B.V.; Viviers, M.Z.; Roux, N.J.; Morris, J.; Bekker, J.P.I.; Roux, M. Neonatal Recognition in Sheep. In Chemical Signals in Vertebrates 12; East, M., Dehnhard, M., Eds.; Springer: New York, NY, USA, 2013; p. 466. [CrossRef]

13. Lisovac, A.; Shooter, D. Volatiles from sheep wool and the modification of wool odour. Small Rumin. Res. 2003, 49, 115-124. [CrossRef]

14. Parlato, M.C.; Porto, S.M. Organized Framework of Main Possible Applications of Sheep Wool Fibers in Building Components Sustainability 2020, 12, 761. [CrossRef]

15. Daria, M.; Krzysztof, L.; Jakub, M. Characteristics of biodegradable textiles used in environmental engineering: A comprehensive review. J. Clean. Prod. 2020, 268, 122129. [CrossRef]

16. Council of Europe. European Pharmacopoeia Vol. 1, 5th ed.; Council of Europe: Strasbourg, France, 2005 ; p. 217.

17. Tsikolia, M.; Opatz, T.; Kauhl, U.; Tabanca, N.; Demirci, B.; TenBroeck, S.H.; Linthicum, K.J.; Bernier, U.R. Trials for Gathering Information on an Unknown Peak in the GC-MS Spectra of Horse and Pony Hair Extracts. Adv. Èntomol. 2021, 9, 100-111. [CrossRef]

18. Yang, L.; Hu, X.P.; Allan, S.A.; Alborn, H.T.; Bernier, U.R. Electrophysiological and Behavioral Responses of the Kudzu Bug, Megacopta cribraria (Hemiptera: Plataspidae), to Volatile Compounds from Kudzu and Soybean Plants. J. Agric. Food Chem. 2019, 67, 4177-4183. [CrossRef]

19. Iscan, G.; Demirci, B.; Demirci, B.; Baser, K.H.C. Headspace solid phase microextraction (HS-SPME) and analysis of Geotrichum fragrans volatiles. Nat. Volatiles Essent. Oils 2015, 2, 45-51.

20. Al-Massarani, S.; Tabanca, N.; Farshori, N.N. Headspace-SPME/GC-MS analysis of the Anethum graveolens volatiles from Saudi Arabia with different fiber coatings. Nat. Volatiles Essent. Oils 2018, 5, 29-34.

21. Kendra, P.E.; Tabanca, N.; Cruz, L.F.; Menocal, O.; Schnell, E.Q.; Carrillo, D. Volatile Emissions and Relative Attraction of the Fungal Symbionts of Tea Shot Hole Borer (Coleoptera: Curculionidae). Biomolecules 2022, 12, 97. [CrossRef]

22. van Den Dool, H.; Kratz, P.D. A generalization of the retention index system including linear temperature programmed gasliquid partition chromatography. J. Chromatogr. A 1963, 11, 463-471. [CrossRef]

23. McLafferty, F.W.; Stauffer, D.B. The Wiley/NBS Registry of Mass Spectral Data; J. Wiley and Sons: New York, NY, USA, 1989 ; p. 1064

24. Hochmuth, D.H. MassFinder 4.0; Hochmuth Scientific Consulting: Hamburg, Germany, 2008.

25. Joulain, D.; König, W.A. The Atlas of Spectra Data of Sesquiterpene Hydrocarbons; E.B. Verlag: Hamburg, Germany, $1998 ;$ p. 658.

26. Jiang, S.; Yang, L.; Bloomquist, J.R. High-throughput screening method for evaluating spatial repellency and vapour toxicity to mosquitoes. Med. Vet. Èntomol. 2019, 33, 388-396. [CrossRef]

27. Kline, D.L. Olfactory attractants for mosquito surveillance and control: 1-octen-3-ol. J. Am. Mosq. Control Assoc. 1994, 10, $280-287$.

28. Kline, D.L.; McKenzie, K.; Bowman, A. CHAPTER 11-Semi-field evaluation of arthropod repellents. In Advances in Arthropod Repellents; Corona, C., Debboun, M., Coats, J., Eds.; Academic Press: Cambridge, MA, USA, 2022; pp. 193-236. [CrossRef]

29. R Studio Team. RStudio: Integrated Development for R; RStudio, Inc.: Boston, MA, USA, 2020; Available online: http://www. rstudio.com/ (accessed on 1 December 2021).

30. Nixon, L.N.; Wong, E.; Johnson, C.B.; Birch, E.J. Nonacidic constituents of volatiles from cooked mutton. J. Agric. Food Chem. 1979, 27, 355-359. [CrossRef]

31. Bueno, M.; Campo, M.M.; Cacho, J.; Ferreira, V.; Escudero, A. A model explaining and predicting lamb flavour from the aroma-active chemical compounds released upon grilling light lamb loins. Meat Sci. 2014, 98, 622-628. [CrossRef]

32. Caporaso, F.; Sink, J.D.; Dimick, P.S.; Mussinan, C.J.; Sanderson, A. Volatile flavor constituents of ovine adipose tissue. J. Agric. Food Chem. 1977, 25, 1230-1234. [CrossRef] 
33. Buttery, R.G.; Ling, L.C.; Teranishi, R.; Mon, T.R. Roasted lamb fat: Basic volatile components. J. Agric. Food Chem. 1977, 25, 1227-1229. [CrossRef]

34. Priolo, A.; Cornu, A.; Prache, S.; Krogmann, M.; Kondjoyan, N.; Micol, D.; Berdagué, J.-L. Fat volatiles tracers of grass feeding in sheep. Meat Sci. 2004, 66, 475-481. [CrossRef]

35. Vasta, V.; Aouadi, D.; Brogna, D.M.R.; Scerra, M.; Luciano, G.; Priolo, A.; Ben Salem, H. Effect of the dietary supplementation of essential oils from rosemary and artemisia on muscle fatty acids and volatile compound profiles in Barbarine lambs. Meat Sci. 2013, 95, 235-241. [CrossRef]

36. Lorenz, G.; Stern, D.J.; Flath, R.A.; Haddon, W.F.; Tillin, S.J.; Teranishi, R. Identification of sheep liver volatiles. J. Agric. Food Chem. 1983, 31, 1052-1057. [CrossRef]

37. Watkins, P.J.; Rose, G.; Warner, R.D.; Dunshea, F.R.; Pethick, D.W. A comparison of solid-phase microextraction (SPME) with simultaneous distillation-extraction (SDE) for the analysis of volatile compounds in heated beef and sheep fats. Meat Sci. 2012, 91, 99-107. [CrossRef]

38. Vasta, V.; Priolo, A. Ruminant fat volatiles as affected by diet. Meat Sci. 2006, 73, 218-228. [CrossRef]

39. Săaková, N.; Sádecká, J.; Lejková, J.; Puškárová, A.; Koreňová, J.; Kolek, E.; Valík, L.; Kuchta, T.; Pangallo, D. Characterization of May bryndza cheese from various regions in Slovakia based on microbiological, molecular and principal volatile odorants examination. J. Food Nutr. Res. 2015, 54, 239-251.

40. Urgeghe, P.P.; Piga, C.; Addis, M.; Di Salvo, R.; Piredda, G.; Scintu, M.F.; Wolf, I.V.; Sanna, G. SPME/GC-MS Characterization of the Volatile Fraction of an Italian PDO Sheep Cheese to Prevalent Lypolitic Ripening: The Case of Fiore Sardo. Food Anal. Methods 2012, 5, 723-730. [CrossRef]

41. Burger, B.V.; Viviers, M.Z.; Le Roux, N.J.; Morris, J.; Bekker, J.P.I.; Le Roux, M. Olfactory Cue Mediated Neonatal Recognition in Sheep, Ovis aries. J. Chem. Ecol. 2011, 37, 1150-1163. [CrossRef]

42. Bueno, M.; Resconi, V.C.; Campo, M.M.; Cacho, J.; Ferreira, V.; Escudero, A. Gas chromatographic-olfactometric characterisation of headspace and mouthspace key aroma compounds in fresh and frozen lamb meat. Food Chem. 2011, 129, 1909-1918. [CrossRef]

43. Shokry, E.; Pereira, J.; Júnior, J.G.M.; Da Cunha, P.H.J.; Filho, A.D.F.N.; Da Silva, J.A.; Fioravanti, M.C.S.; De Oliveira, A.E.; Filho, N.R.A. Earwax metabolomics: An innovative pilot metabolic profiling study for assessing metabolic changes in ewes during periparturition period. PLoS ONE 2017, 12, e0183538. [CrossRef]

44. Chen, J.; Ho, C.-T. Volatile Compounds Identified in Preserved Duck Eggs. In Flavor Chemistry of Ethnic Foods, 1st ed.; Shahidi, F., Ho, C.-T., Eds.; Springer Science/Business Media: New York, NY, USA, 1999; pp. 263-268.

45. Kubota, K.; Watanabe, K.; Kobayashi, A. Novel Dithiazine Compounds in Volatile Components from Cooked Sakuraebi (Sergia lucensHansen). Agric. Biol. Chem. 1988, 52, 1537-1540. [CrossRef]

46. Day, C.S.; Hansen, T.J.; Keefer, L.K. Stereochemistry of thialdine. J. Heterocycl. Chem. 1982, 19, 1301-1304. [CrossRef]

47. Aparicio-Ruiz, R.; Garcia-González, D.L.; Morales, M.T.; Lobo-Prieto, A.; Romero, I. Comparison of two analytical methods validated for the determination of volatile compounds in virgin olive oil: GC-FID vs GC-MS. Talanta 2018, 187, 133-141. [CrossRef]

48. Wondwosen, B.; Birgersson, G.; Seyoum, E.; Tekie, H.; Torto, B.; Fillinger, U.; Hill, S.R.; Ignell, R. Rice volatiles lure gravid malaria mosquitoes, Anopheles arabiensis. Sci. Rep. 2016, 6, 37930. [CrossRef]

49. Raji, J.I.; Melo, N.; Castillo, J.S.; Gonzalez, S.; Saldana, V.; Stensmyr, M.C.; DeGennaro, M. Aedes aegypti Mosquitoes Detect Acidic Volatiles Found in Human Odor Using the IR8a Pathway. Curr. Biol. 2019, 29, 1253-1262. [CrossRef]

50. Afify, A.; Galizia, C.G. Chemosensory Cues for Mosquito Oviposition Site Selection. J. Med. Èntomol. 2015, 52, 120-130. [CrossRef]

51. Nyasembe, V.O.; Teal, P.E.; Mukabana, W.R.; Tumlinson, J.H.; Torto, B. Behavioural response of the malaria vector Anopheles gambiae to host plant volatiles and synthetic blends. Parasites Vectors 2012, 5, 234. [CrossRef]

52. Jacob, J.W.; Tchouassi, D.P.; Lagat, Z.O.; Mathenge, E.M.; Mweresa, C.K.; Torto, B. Independent and interactive effect of plant- and mammalian- based odors on the response of the malaria vector, Anopheles gambiae. Acta Trop. 2018, 185, 98-106. [CrossRef]

53. Robinson, A.; Busula, A.; Voets, M.A.; Beshir, K.B.; Caulfield, J.C.; Powers, S.J.; Verhulst, N.; Winskill, P.; Muwanguzi, J.; Birkett, M.; et al. Plasmodium-associated changes in human odor attract mosquitoes. Proc. Natl. Acad. Sci. USA 2018, 115, E4209-E4218. [CrossRef]

54. Owino, E.A.; Sang, R.; Sole, C.L.; Pirk, C.; Mbogo, C.; Torto, B. An improved odor bait for monitoring populations of Aedes aegypti-vectors of dengue and chikungunya viruses in Kenya. Parasites Vectors 2015, 8, 1-12. [CrossRef]

55. Qiu, Y.T.; Smallegange, R.C.; Smid, H.M.; van Loon, J.J.A.; Galimard, A.M.S.; Posthumus, M.A.; van Beek, T.A.; Takken, W. GC-EAG analysis of human odours that attract the malaria mosquito Anopheles gambiae sensu stricto. Proc. Neth. Entomol. Soc. Meet 2004, 15, 59-64.

56. Lahondere, C.; Vinauger, C.; Okubo, R.P.; Wolff, G.H.; Chan, J.K.; Akbari, O.S.; Riffell, J.A. The olfactory basis of orchid pollination by mosquitoes. Proc. Natl. Acad. Sci. USA 2020, 117, 708-716. [CrossRef]

57. Wondwosen, B.; Birgersson, G.; Tekie, H.; Torto, B.; Ignell, R.; Hill, S.R. Sweet attraction: Sugarcane pollen-associated volatiles attract gravid Anopheles arabiensis. Malar. J. 2018, 17, 1-9. [CrossRef]

58. Wooding, M.; Naudé, Y.; Rohwer, E.; Bouwer, M. Controlling mosquitoes with semiochemicals: A review. Parasites Vectors 2020, 13, 1-20. [CrossRef]

59. Majumder, S.; Ghosh, A.; Chakraborty, S.; Bhattacharya, M. GC-MS analysis reveals Dendrobium candidum is a mosquito-attractant orchid with mosquitocidal compounds. Int. J. Mosq. Res. 2020, 7, 9-12. [CrossRef] 
60. Bernier, U.R.; Kline, D.L.; Barnard, D.; Posey, K.; Booth, M.; Yost, R.A. Chemical Compounds That Attract Arthropods-Patent 2001. U.S. Patent 6,267,953 BI, 31 July 2001. Available online: https:/ / digitalcommons.unl.edu/usdaarsfacpub/973 (accessed on 15 February 2022).

61. Ikeshoji, T.; Mulla, M.S. Attractancy and repellency of alkyl carbonyl compounds for mosquito oviposition. Med. Entomol. Zool. 1974, 25, 89-94. [CrossRef]

62. Bernier, U.R.; Booth, M.M.; Yost, R.A. Analysis of Human Skin Emanations by Gas Chromatography/Mass Spectrometry. 1. Thermal Desorption of Attractants for the Yellow Fever Mosquito (Aedes aegypti) from Handled Glass Beads. Anal. Chem. 1999, 71, 1-7. [CrossRef] [PubMed]

63. Logan, J.G.; Birkett, M.A.; Clark, S.J.; Powers, S.; Seal, N.J.; Wadhams, L.J.; (Luntz), A.J.M.; Pickett, J.A. Identification of HumanDerived Volatile Chemicals that Interfere with Attraction of Aedes aegypti Mosquitoes. J. Chem. Ecol. 2008, 34, 308-322. [CrossRef] [PubMed]

64. Torres-Estrada, J.L.; Meza-Alvarez, R.A.; Cibrian-Tovar, J.; Rodríguez-López, M.H.; Arredondo-Jiménez, J.I.; Cruz-López, L.; Rojas-Leon, J.C. Vegetation-derived cues for the selection of oviposition substrates by Anopheles albimanus under laboratory conditions. J. Am. Mosq. Control Assoc. 2005, 21, 344-349. [CrossRef]

65. De Moraes, C.M.; Stanczyk, N.M.; Betz, H.S.; Pulido, H.; Sim, D.G.; Read, A.F.; Mescher, M.C. Malaria-induced changes in host odors enhance mosquito attraction. Proc. Natl. Acad. Sci. USA 2014, 111, 11079-11084. [CrossRef] [PubMed]

66. Jaleta, K.T.; Hill, S.R.; Birgersson, G.; Tekie, H.; Ignell, R. Chicken volatiles repel host-seeking malaria mosquitoes. Malar. J. 2016, 15, 354. [CrossRef]

67. Collins, L.E.; Blackwell, A. Electroantennogram studies of potential oviposition attractants for Toxorhynchites moctezuma and T. amboinensis mosquitoes. Physiol. Ėntomol. 1998, 23, 214-219. [CrossRef]

68. Tauxe, G.M.; MacWilliam, D.; Boyle, S.M.; Guda, T.; Ray, A. Targeting a Dual Detector of Skin and $\mathrm{CO}_{2}$ to Modify Mosquito Host Seeking. Cell 2013, 155, 1365-1379. [CrossRef]

69. Verhulst, N.O.; Beijleveld, H.; Qiu, Y.T.; Maliepaard, C.; Verduyn, W.; Haasnoot, G.W.; Claas, F.H.; Mumm, R.; Bouwmeester, H.J.; Takken, W.; et al. Relation between HLA genes, human skin volatiles and attractiveness of humans to malaria mosquitoes. Infect. Genet. Evol. 2013, 18, 87-93. [CrossRef]

70. Lindh, J.M.; Kännaste, A.; Knols, B.G.J.; Faye, I.; Borg-Karlson, A.-K. Oviposition Responses of Anopheles gambiae s.s. (Diptera: Culicidae) and Identification of Volatiles from Bacteria-Containing Solutions. J. Med. Ėntomol. 2008, 45, 1039-1049. [CrossRef]

71. Dou, Z.; Madan, A.; Carlson, J.S.; Chung, J.; Spoleti, T.; Dimopoulos, G.; Cammarato, A.; Mittal, R. Acoustotactic response of mosquitoes in untethered flight to incidental sound. Sci. Rep. 2021, 11, 1-9. [CrossRef]

72. Vinauger, C.; Van Breugel, F.; Locke, L.T.; Tobin, K.K.; Dickinson, M.H.; Fairhall, A.L.; Akbari, O.S.; Riffell, J.A. Visual-Olfactory Integration in the Human Disease Vector Mosquito Aedes aegypti. Curr. Biol. 2019, 29, 2509-2516. [CrossRef] [PubMed] 